\title{
Facility Gaps for Players at International Cricket Stadiums in Sri Lanka vs. Australia
}

\author{
H. R. Dharmadasa", H. P. N. Perera \\ Department of Sports Science, Faculty of Applied Sciences, University of Sri Jayewardenepura, Sri Lanka
}

Received January 29, 2021; Revised March 28, 2021; Accepted April 18, 2021

\section{Cite This Paper in the following Citation Styles}

(a): [1] H. R. Dharmadasa, H. P. N. Perera, "Facility Gaps for Players at International Cricket Stadiums in Sri Lanka vs. Australia," International Journal of Human Movement and Sports Sciences, Vol. 9, No. 3, pp. 590 - 594, 2021. DOI: 10.13189/saj.2021.090327.

(b): H. R. Dharmadasa, H. P. N. Perera (2021). Facility Gaps for Players at International Cricket Stadiums in Sri Lanka vs. Australia. International Journal of Human Movement and Sports Sciences, 9(3), 590 - 594. DOI: 10.13189/saj.2021.090327.

Copyright $C 2021$ by authors, all rights reserved. Authors agree that this article remains permanently open access under the terms of the Creative Commons Attribution License 4.0 International License

\begin{abstract}
The main intention of the study is to identify the differences between facilities available for players at International Cricket Stadiums in Sri Lanka and Australia. To successfully explore the differences, the study was conducted using a qualitative research approach. Data were gathered primarily through interviews and observations. Photo-elicitation was the data analysis technique used and two sites: Optus Stadium in Western Australia and R. Premadasa Cricket Stadium in Sri Lanka were focused under this study. Accordingly, the study identifies facilities available for players at R. Premadasa Cricket Stadium, Sri Lanka and Optus Stadium, Western Australia separately. In total, seven managerial level interviewees took part in the study. Four interviewees came from Western Australia and three interviewees from Sri Lanka. These participants were directly linked with the two research sites and perception of these managerial level individuals was considered under the current study. The findings of the study confirm that there is a difference between R. Premadasa Cricket Stadium and Optus Stadium, in terms of facilities available for players. This reflects a gap between facilities available for players at International Cricket Stadiums in Sri Lanka and Australia.
\end{abstract}

Keywords Facility, R. Premadasa Cricket Stadium, Optus Stadium, Cricket Stadium, International Cricket Stadiums

\section{Introduction}

The sports performance of Sri Lanka in international arena is not appealing as per the records [1], [2]. This was different from Cricket [3], [4]. Sri Lanka cricket entered a new era with the 1996 Cricket World Cup winning. Since then, Sri Lankan cricket have brought many glories to the nation. After the 1996 ICC (International Cricket Council) Cricket world cup triumph, Lankan lions became the consecutive runners up in the years of 2007 and 2011 [5]. After settling for the runners up position in years 2009 and 2012, the Lankan lions became the world champions in the shorter format of the game by winning the 2014 ICC Twenty20 Cricket World Cup [6].

With this rich victorious cricket history, the sports facilities available for cricket in Sri Lanka are more than that of other sports [7]. According to [8], it is best to have multiple facilities for cricket as it is the most successful sport and has earned fame for Sri Lanka. The features offered to the cricketers in these facilities are even more significant than the number of facilities [9].

Therefore, there arises a necessity to study and identify the differences between facilities available for players at International Cricket Stadiums in Sri Lanka and Australia.

A place that is designed for a specific function is recognized as a facility [10]. When hosting sporting events this space is recognized as a sports facility [11]. [12] the interpretation of a sports facility is that they are Physical Education Labs where structured physical activities are performed. 
There are various capital projects that can generate economic benefits. However, these projects are not able to have an impact on community as sports facilities are able to [13]. At one point of the paper on the study by [13] state that sports facilities will promote the city where it is located. However, on another point the study by [13] discuss that there is no evidence that construction of sports facility has promote the city and attracted more business.

[14] discussed the importance of a proper sports facility to its main users. According to [14], Athletes are the main users of a sports facility and it is important to consider the benefits a sports facility offers to athletes. Accordingly, the design and location of a dressing room is a factor of consideration when it comes to players preferences. Finish of the room, furniture and equipment are discussed as important elements of the dressing room [14].

\section{Materials and Methods}

To successfully explore the difference between facilities available for players at International Cricket Stadiums in Sri Lanka and Australia it is important to explore the view of the stakeholders focusing specially on managerial stakeholders. Their experience, knowledge and views were explored and accessed. When a researcher is focused on understanding an individual's life experiences it is necessary to adopt a qualitative research strategy [15]. Furthermore, [16] noted that when assigning meanings to a person's thoughts, it is important to understand emotions behind those thoughts. Without experiencing the emotions properly the correct interpretations cannot be given. Therefore, to properly interpret these subjective maters it is important to use a qualitative method. Though analytical models could be used to understand the attributes of an object, it is not suitable to understand the direct sensory experiences [16]. Accordingly, this study was conducted as a qualitative research study. Data were gathered primarily through interviews and observations.

Photo-elicitation was used as the data analysis technique. Photo-elicitation means the use of photographs in a research study to explain something [17]. As [18] stated, photo-elicitation is a more effective approach than words alone. [18] went on to explain that, words will utilize only a part of the brain of the reader whereas words and images will utilize more greater capacity of the brain and provide a better understanding.

Since the research sites are from two different countries, the research participants were also from diverse backgrounds. In total, seven (07) managerial level interviewees took part in the study. Three (03) interviewees were from Sri Lanka related to R. Premadasa Cricket Stadium and four (04) managerial level interviewees were from Optus Stadium, Western Australia.

\section{Results and Discussions}

Data analysis revealed that the team dressing room facilities at Optus Stadium was very modest. As shown in figure 1, it had modern furniture. Furthermore, the interior of the team dressing rooms were decorated according to the team that will occupy that space. The team dressing room of the Optus stadium was decorated with "Frementle Dockers" team colour and logo (figure 1). View of [19] for the question of intention behind decorating the team dressing room was that, there is a psychological effect on the players. This view was verified by the researchers own experiences as it gave a warm welcome felling. The researchers first impression to the team dressing rooms of R. Premadasa Cricket Stadium was the opposite. The chois of furniture at the team dressing room of R. Premadasa Cricket Stadiums were outdated (figure 2). Moreover, they were not arranged in an organized manner. However, at the team dressing room of R. Premadasa Cricket Stadium more space was assigned to individual player. Thoughts of interviewees was gathered on the layout of the dressing rooms. According to [8] the layout of the team dressing room of R. Premadasa Cricket Stadiums had a spacious look.

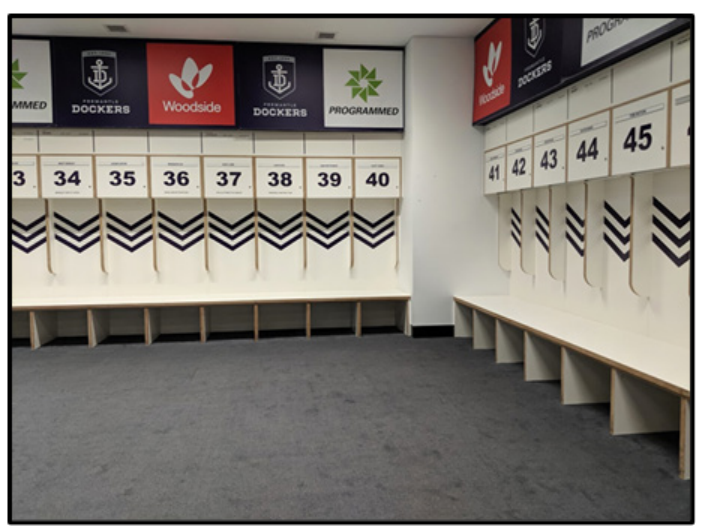

Source: Survey Data, Oct 2019

Figure 1. Team dressing room at Optus Stadium decorated with Frementle Dockers colours and logo

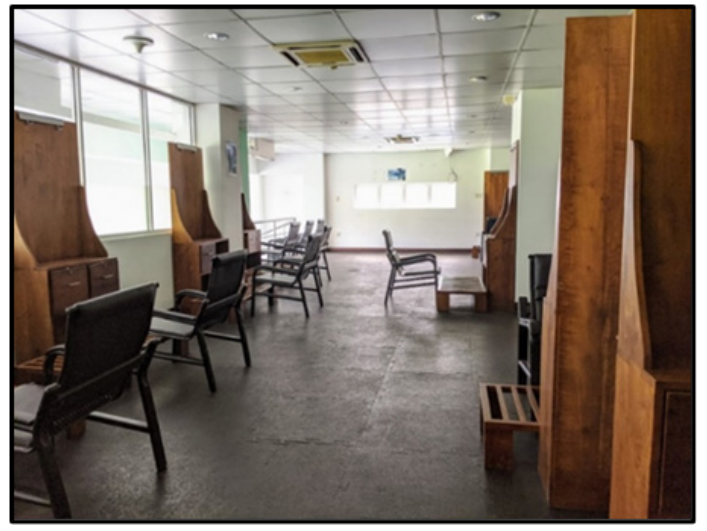

Source: Survey Data, Dec 2019

Figure 2. Team dressing rooms at R. Premadasa Cricket Stadium 
At Optus Stadium, room adjoining the team dressing room was the Ice and Hot bath facilities available for the players (figure 3). As [20] stated, use of water in sports for recovery was adapted by observation of the animals in the wild. An animal will apply water by licking the injured area. From the day of their existence, animals have been using water to heal and recover themselves [20]. These comments were made by [20] when asked for view of use of water as recovery technique. The room contained six separate baths and the temperature of the water in baths can be adjusted according to preference of the player. Figure 4 provide a visually representation of the Ice and Hot bath facilities at R. Premadasa Cricket Stadium. There is only one bath for each dressing room and there is no temperature regulator. It means temperature of the water must be manually adjusted.

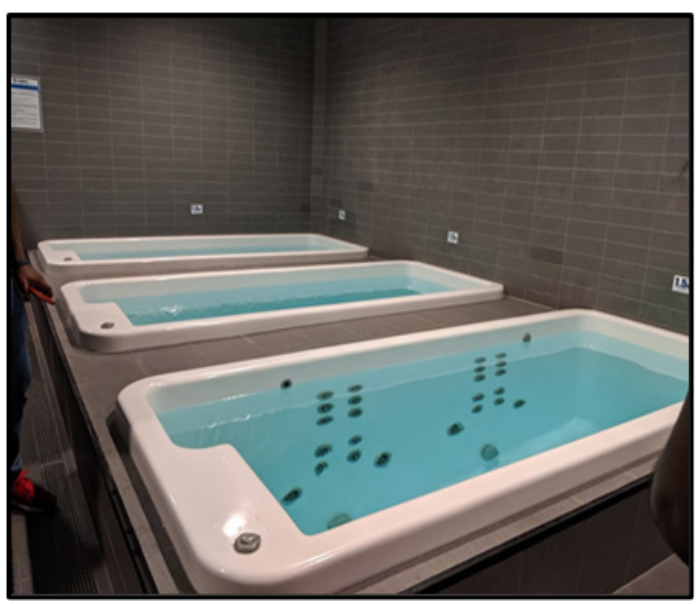

Source: Survey Data, Oct 2019

Figure 3. Ice and Hot water baths at Optus Stadium

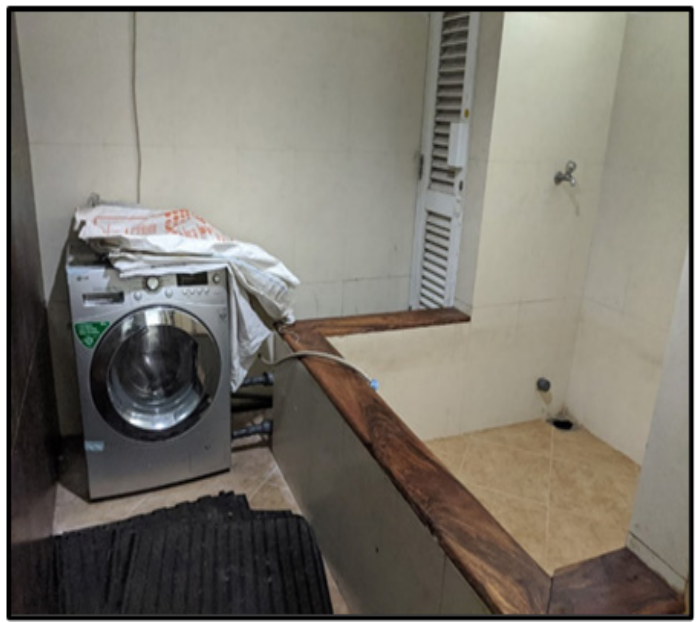

Source: Survey Data, Dec 2019

Figure 4. Ice and Hot water bath facility at R. Premadasa Cricket Stadium

Within the team dressing room space at Optus Stadium there is an area assigned for players to be physically active (figure 5). An open-ended question was asked by the interviewees related to the indoor physical active area. [20] respond to this that although this is an indoor space, the surface is specially designed to accommodate the cricket shoes with spicks underneath the sole. At R. Premadasa Cricket Stadium there were no indoor space for cricketers to do there warm up activities and drills. Hence, the players must use the outdoor main playing area for basic warmup activities and drills as well.

Another essential feature at a cricket stadium for players are the Medical room facilities. Both at R. Premadasa Cricket Stadium and Optus stadium the Medical room facilities were available. However, when considering the convenience to the players the two rooms (Medical rooms) were at different ends.

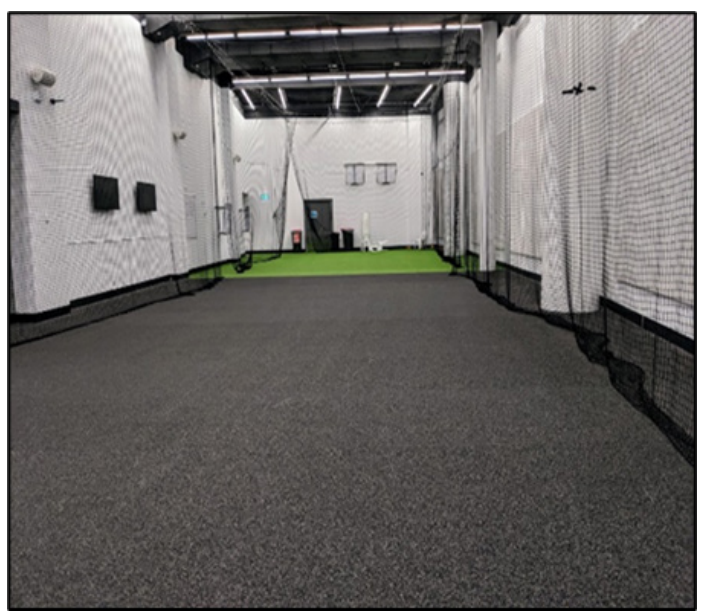

Source: Survey Data, Oct 2019

Figure 5. Indoor physically activity area at Optus Stadium

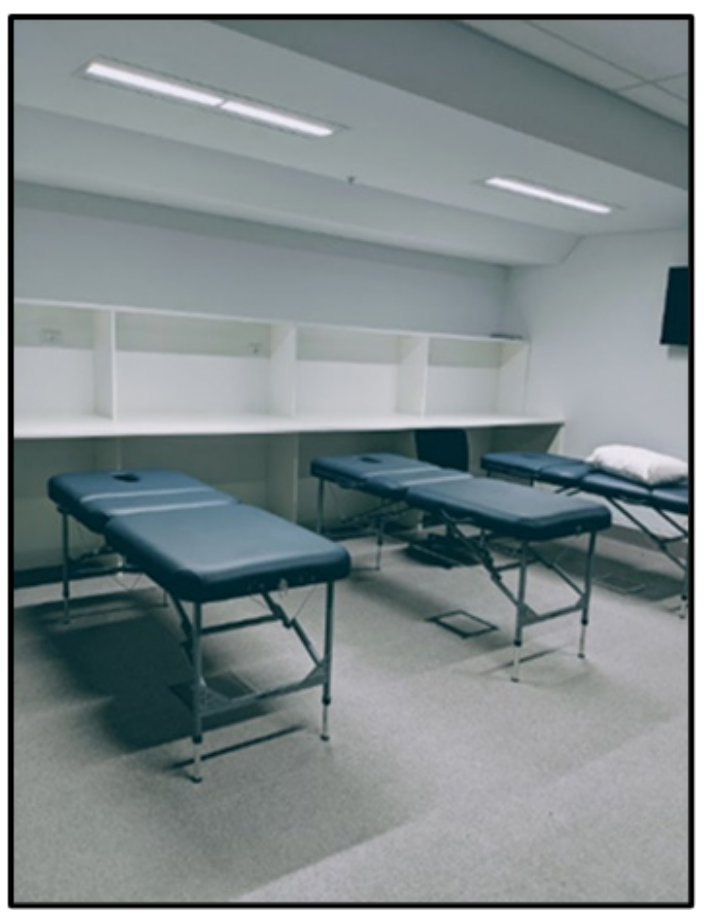

Source: Survey Data, Oct 2019

Figure 6. Medical Room facility at Optus Stadium

The Medical room at Optus Stadium adjoins the dressing 
room in the same floor level (figure 6). This make it easier and convenient for the players to get access. The medical room at R. Premadasa Cricket Stadium was located on the floor below the dressing rooms. It means that a player wanting to access the Medical room at R. Premadasa Cricket Stadium will have to walk their way down the stairs and entre the Medical facility.

The Optus Stadium was like a treasure hunt. Door after door led to various different features of the dressing room. One of those discoveries was the Seminar room (figure 7). Seminar room is a feature that was unique to Optus Stadium when compared with R. Premadasa Cricket Stadium. Each team had access to a Seminar room and these rooms facilitate team talks, analyzing of match data and match day team seminars.

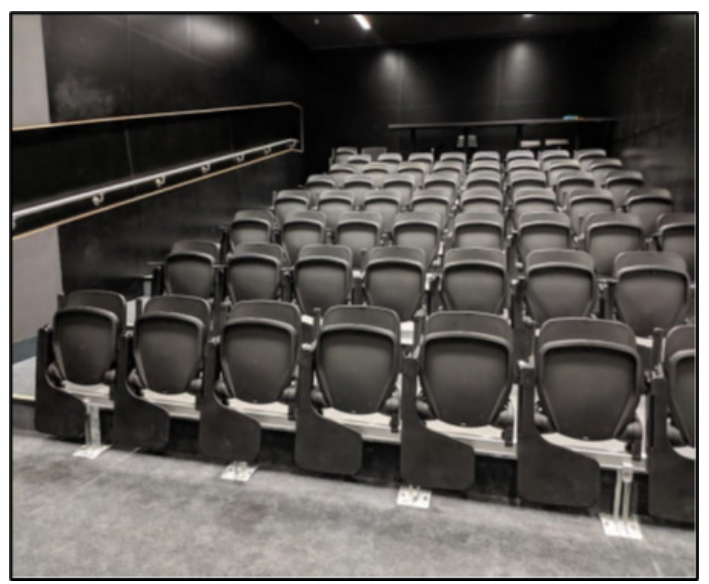

Source: Survey Data, Oct 2019

Figure 7. Seminar room at Optus Stadium

\section{Conclusions}

The primary intention of the study was to identify the differences between facilities available for players at International Cricket Stadiums in Sri Lanka and Australia. The study revealed the various facilities available for players at Optus Stadium and R. Premadasa Cricket Stadium and the differences between them.

It was revealed that both Optus Stadium of Western Australia and R. Premadasa Cricket Stadium of Sri Lanka offered similar variety of facilities. Namely there are team dressing rooms, ice and hot bath facilities and medical rooms. However, the study revealed the differences between facilities available for players at Optus Stadium and R. Premadasa Cricket Stadium, for example, the team dressing rooms. The interior of the team dressing room at Optus Stadium was modest and very tidy. At one point the researcher claimed that it gave an invitational sensation. At R. Premadasa Cricket Stadium the team dressing room had a spacious layout. However, the furniture was outdated.

Ice and hot bath facilities at Optus Stadium offered many features such as in-built temperature regulator and the jacuzzi bath option. These features were not available at ice and hot bath facilities of R. Premadasa Cricket Stadium. However, a major difference was the number of baths. Optus Stadium offered six (06) baths per team in contrast to the one (01) bath per team offered at R. Premadasa Cricket Stadium.

Results and discussions of the study revealed that medical room facilities is a key component for an International cricket stadium. Fast and easy access is vital for a key feature like the medical room facilities. R. Premadasa Cricket Stadium failed in providing fast and easy access to the medical rooms from the team dressing rooms, as it was located on a separate floor level from the team dressing room.

There were facilities offered to players at Optus Stadium that were not available at R. Premadasa Cricket Stadium. Namely there are indoor space for physical activities and seminar rooms. Optus Stadium had a specially designed space withing the team dressing room area for its players to be physically active indoors. At R. Premadasa Cricket Stadium there was no such facility. Accordingly, the players had to utilize the outdoor playing area for warm-ups and drills. Similarly, at Optus Stadium there was a specially designed space to host team talks, analyze match data and match day team seminars. The seminar room facilities were not available at $\mathrm{R}$. Premadasa Cricket Stadium. With that it can be stated that, there are marginal differences in the team dressing room and medical room facilities and clear difference in ice and hot bath facilities, space for physical activities and seminar rooms between Optus Stadium and R. Premadasa Cricket Stadium.

Based on the observations made, the findings of interview and data analysis through photo elicitation, it can be concluded that there is a visible gap between facilities available for players at International Cricket Stadiums in Sri Lanka and Australia.

\section{Acknowledgements}

To successfully reach the intended outcomes of the study, the participation of the seven (07) interviewees are highly appreciated. The knowledge and the experience shared with the researchers allowed this study to be successful. Furthermore, it must be stated that granting permission to take photographs at the two research sites contributed tremendously to the effectiveness of the study.

\section{REFERENCES}

[1] Perera, H., "Does the Coach Leadership Behavior Mediates the Influence of Factors Affecting Coach Leadership Behavioral Styles on Team Success," International Journal of Human Movement and Sports Sciences, Vol. 7, No. 3, pp. 51-57, 2019. DOI: 10.13189/saj.2019.070302. 
[2] Perera, H., Jusoh, M., Azam, S. \& Sudasinghe, S. "InInfluence of Goal Orientation on Players' Performance with Special Reference to Sri Lanka National Team Sports," International Journal of Human Movement and Sports Sciences, Vol. 7, No. 4, pp. 89-97, 2019. DOI: 10.13189/saj.2019.070404.

[3] Perera, H. \& Pushpakumari, M., "The perception of Athletes on the Factors Affecting to Coach Leadership Behavior styles: An empirical study on leadership styles Exhibited by the Coaches of State Universities in Western Province- Sri Lanka". International Journal of Multidisciplinary Studies (IJMS), Vol. 2, No. 2, pp. 83-91, 2015, DOI: 10.4038/ijms.v2i2.77.

[4] Perera, H., Jusoh, M., Azam, S. \& Sudasinghe, S., "The Perceived Significance of Spirituality on Sri Lankan National Team Players' Performance", The Journal of Social Sciences Research, Vol. 5, No. 10, pp. 1501-1506, 2019, DOI: 10.32861 /jssr.510.1501.1506.

[5] The Editors of Encyclopaedia Britannica, Cricket World Cup, Online available from https://www.britannica.com/sports/Cr icket-World-Cup

[6] Longmore, A, Twenty20 Cricket World Cup, Online available from https://www.britannica.com/sports/Twenty20 -cricket

[7] Dharmadasa, H. R. \& Perera, H. P. N., "Identifying the gaps in facility design with special preference to spectators between international cricket stadiums in Sri Lanka and Australia", 3rd National Research Symposium on Management, Faculty of Management Studies, Rajarata University of Sri Lanka, pp. 99, 2020.

[8] Kumara, A., 2019. Facilities for players at R. Premadasa Cricket Stadium [Interview] (12 December 2019).

[9] Dharmadasa, H. R. \& Perera, H. P. N., "Differences between Facilities Available for Players at International Cricket Stadiums in Sri Lanka and Australia", 7th International Conference of Multidisciplinary Approaches (iCMA),
Faculty of Graduate Studies, University of Sri Jayewardenepura, Nugegoda, pp. 89, 2020.

[10] Varcoe, B., "Implications for facility management of the changing business climate", Facilities, pp. 383 - 391, 2000.

[11] Walker, M. L. \& Stotlar, D. K., Sports Facility Management, Jones and Bartlett Publishers, Sudbury, 1997.

[12] Rintaugu, E. G. \& Nteere, J. S., “Availability and adequacy of sports facilities and equipment in selected secondary schools in Kenya", West African Journal of Physical and Health Education, 2011.

[13] Johnson, A. \& Sack, A., "Assessing the Value of Sports Facilities: The Importance of Noneconomic Factors", Economic Development Quarterly, Vol. 4, No. 10, pp. 369-381, 1996

[14] Hagen, G. A., "New Features in Gymnasium Planning: A Description of the Wakefield, Michigan, Facilities", The Journal of Health and Physical Education, Vol. 6, No. 6, pp. 20-23, 1935.

[15] Shaw, E., "A guide to the qualitative research process: evidence from a small firm study", Qualitative Market Research: An International Journal, 1999.

[16] Taylor, S. S. \& Hansen, H., "Finding form: Looking at the field of organizational aesthetics", Journal of Management Studies, Vol. 6, No. 42, pp. 1211-1231, 2005.

[17] Lapenta, F., "Some theoretical and methodological views on photo-elicitation", The SAGE handbook of visual research methods, 2011.

[18] Harper, D., Talking about pictures: A case for photo elicitation, Visual studies, Vol. 1, No. 7, pp.13-26, 2002.

[19] Klymovich, C., 2019. Facilities available for players at Optus Stadium [Interview] (24 September 2019).

[20] Pereira, H., 2019. Facilities available for players at Optus Stadium [Interview] (1 October 2019). 